\title{
Analysis of Plan Irregular Building Supported in Different Soil Stratum
}

\author{
P.S. Anil Kumar and Vinayak Vijapur
}

\begin{abstract}
Buildings with plan irregularity are commonly encountered when there is a scope for maximum utilization of the minimum available space. Also, these buildings respond differently when located in various seismic zones. One of the major problems associated with irregular buildings is torsion. It also leads to difference in the stress induced in different wings of the building leading to stress concentration at the re-entrant corner. This study focuses on the response of the building with a re-entrant corner located in various soils. The major objective is to study the response of a $C, H, L$ and $T$ shape building in different soil at seismic zone $I V$ and also, to compare the buildings containing re-entrant corners with a building of regular plan configuration by performing linear dynamic analysis. While modeling, the plan area of all the models has been made equal in order to facilitate comparison. The results obtained are compared for different soil stratum in terms of storey drift, base shear, and storey displacement. Along with this, the acceleration and time period also studied. When the re-entrant building was compared with regular building, it was observed that the former undergoes larger storey displacement and drift than the latter. Buildings with re-entrant corner are more vulnerable to seismic damages and are susceptible to earthquake corresponding to time periods of lower order; hence, the building plan must be of regular configuration in order to possess significant seismic resistance.
\end{abstract}

Keywords--- RC Building, Regular, Plan Irregular, Response Spectrum, ETABS 2015

\section{INTRODUCTION}

$I_{a}^{\mathrm{N}}$ $\mathrm{N}$ modern urban infrastructure irregular buildings constitute a large portion. The configuration of the buildings are decided by the group of people involved in the construction including the owner, structural engineer, contractor, architect and local authorities who contribute in overall planning and finalizing the structural system. When these structures are located on high seismic zone, the structural engineers play an important role and become more challenging for them in designing the building as earthquake resistant and to perform well against the earthquake motions.

P.S. Anil Kumar, PG Student, Department of Civil Engineering, Government Engineering College, Haveri, Karnataka, India. E-mail:anicoorg88@gmail.com

Vinayak Vijapur, Assistant Professor, Department of Civil Engineering, Government Engineering College, Haveri, Karnataka, India. E-mail:vinayaka_pv@yahoo.co.in

DOI:10.9756/BIJMMI.8149
Nowadays the buildings are usually built in with one or more irregularities it may be horizontal or vertical in order to have a good aesthetic and architectural appearance. But significant destruction has been resulted in building of an asymmetry plan due to increase in the stress of certain elements. In multi storey buildings earthquake damages are found in weak point of the structure. So to perform well against the earthquake the building should possess high stiffness, adequate strength, simple configuration and ductile.

Indian code for seismic resistant design of buildings, IS 1893 (PART 1) classifies the whole of India into four seismic zones. The considered building models have been studied for the seismic zone IV. There are two major problems associated with re-entrant corners. One is torsion and another is that they tend to produce differential motion between different wings of the building leading to local stress concentration at the re-entrant corner. Re-entrant corner arises in case of plans in H, I, T, L, C \& U shapes.

\section{A. Structural Irregularities in the Buildings}

The structured irregularities in the buildings can be broadly classified into two types i.e. plan irregularities and vertical irregularities. The building is said to be vertical irregular if it possess irregular distribution of mass strength and stiffness along the height of the building. If it has irregular distribution along the plan then it is termed as plan irregular. Some buildings are originally planned and designed to build irregular but in some case the building undergo irregularity accidently due to many reason like false construction practice and usage of non-engineering elements.

\section{B. Horizontal Structural Irregularities}

- Torsional Irregularity is defined to exist where the maximum story drift, computed including accidental torsion, at one end of the structure transverse to an axis more than 1.2 times the average of the story drifts at the two ends of the structure. Torsional irregularity requirements in the reference sections apply only to structures in which the diaphragms are rigid or semi-rigid.

- Extreme Torsional Irregularity is defined to exist where the maximum story drift, computed including accidental torsion, at one end of the structure transverse to an axis is more than 1.4 times the average of the story drifts at the two ends of the structure. Extreme torsional irregularity requirements in the reference sections apply only to structures in which diaphragms are rigid or semi-rigid. 
- Reentrant Corner Irregularity is defined to exist where both plan projections of the structure beyond a reentrant corner are greater than $15 \%$ of the plan dimension of the structure in the given direction.

- Diaphragm Discontinuity Irregularity is defined to exist where there are diaphragms with abrupt discontinuities or variations in stiffness, including those having cutout or open areas greater than $50 \%$ of the gross enclosed diaphragm area, or changes in effective diaphragm stiffness of more than $50 \%$ from one story to the next.

- Out-of-Plane Offsets Irregularity is defined to exist where there are discontinuities in a lateral forceresistance path, such as out-of-plane offsets of the vertical elements.

- Nonparallel Systems-Irregularity is defined to exist where the vertical lateral force-resisting elements are not parallel to or symmetric about the major orthogonal axes of the seismic force-resisting system.

\section{METHOD OF ANALYSIS OF STRUCTURE}

The seismic analysis should be carried out for the buildings that have lack of resistance to earthquake forces. Seismic analysis will consider dynamic effects hence the exact analysis sometimes become complex. However for simple regular structures equivalent linear static analysis is sufficient one. This type of analysis will be carried out for regular and low rise buildings and this method will give good results for this type of buildings. Dynamic analysis will be carried out for the building as specified by code IS 1893-2002 (part1). Dynamic analysis will be carried out either by Response spectrum method or site specific Time history method. In present study analysis is carried out using Response spectrum method

\section{A. Response Spectrum Method}

The representation of maximum response of idealized single degree freedom system having certain period and damping, during earthquake ground motions. This analysis is carried out according to the code IS 1893-2002 (part1). Here type of soil, seismic zone factor should be entered from IS 1893-2002(part1). The standard response spectra for type of soil considered is applied to building for the analysis in ETABS 2015 software. Following diagram shows the standard response spectrum for medium soil type and that can be given in the form of time period versus spectral acceleration coefficient $(\mathrm{Sa} / \mathrm{g})$.

\section{DETAILS OF THE MODELS}

The buildings that are considered for the analysis have been modeled in ETABS 2015 software. Here buildings with regular and irregular configuration having 10storeys are modeled in ETABS 2015. For the present work, $(\mathrm{G}+9)$ storey building with storey height 3 meter for all models, and is located in seismic zone IV. For irregular buildings the modeling has been made according to IS code. Details of the Building are given in table-1 below.

\section{A. Regular Model}

This model is without irregularity in plan may be called as regular building. The model has 10 storeys, having the individual storey height of 3 meter. In plan it has 4 and 5 bays of 4 meter width in $\mathrm{X}$ and $\mathrm{Y}$ direction respectively.

\section{B. Plan irregular Model}

In this case the models are done with the shape of $\mathrm{C}, \mathrm{H}, \mathrm{T}$ and $\mathrm{L}$ having the re-entrant corner. However the areas of the models are kept same so as to make the comparison with regular model.

The following models are considered in the present work.

- Model 1: Rectangular Shape RC frame with 4 bays in $\mathrm{X}$ direction and 5 bays in $\mathrm{T}$ direction. The length of the each bay is 4 meter.

- Model 2: C shape RC frame building with 6 bays in X direction and 5 bays in $\mathrm{Y}$ direction with each bay of length 4 meter. $\mathrm{A} / \mathrm{L}$ ratio is 0.5

- Model 4: H shape RC frame building with 6 bays in X direction and 5 bays in $\mathrm{Y}$ direction of bay length 4 meter. $\mathrm{A} / \mathrm{L}$ ratio is 0.25

- Model 4: L shape RC frame building with 6 bays in both direction having the bay length 4 meter. $\mathrm{A} / \mathrm{L}$ ratio is 0.66 .

- Model 5: T shape RC frame building with 6 bays in both $\mathrm{X}$ and $\mathrm{Y}$ direction, each bay length is 4 meter. $\mathrm{A} / \mathrm{L}$ ratio is 0.66 .

The areas of the entire five models were kept same.

Table 1: General Data of the Building

\begin{tabular}{|l|l|l|}
\hline Sl. No. & Description & Data \\
\hline 1 & Number of Stories & 10 \\
\hline 2 & The building Frame system & OMRF \\
\hline 3 & Building Use & Residential \\
\hline 4 & Floor Height & 3 meter \\
\hline 5 & \multirow{2}{*}{ Types of soil } & Hard \\
\cline { 3 - 3 } & & Medium \\
\cline { 2 - 3 } & & Soft \\
\hline 6 & Support Condition & Fixed \\
\hline Material Properties & M30 \\
\hline 7 & Grade of Concrete & Fe 415 \\
\hline 8 & Grade of Steel & $5000 \sqrt{\mathrm{fck}}$ \\
\hline 9 & Young's modules of Concrete & $25 \mathrm{kN} / \mathrm{m}^{3}$ \\
\hline 10 & Density of Concrete & $20 \mathrm{kN} / \mathrm{m}^{3}$ \\
\hline 11 & Density of Masonry & 0.2 \\
\hline 12 & Poisson's ratio & $400 \mathrm{~mm} \times 500 \mathrm{~mm}$ \\
\hline Structural Members & $230 \mathrm{~mm} \times 400 \mathrm{~mm}$ \\
\hline 13 & Column Size & $230 \mathrm{~mm}$ \\
\hline 14 & Beam Size & $150 \mathrm{~mm}$ \\
\hline 15 & Thickness of Wall & \\
\hline 16 & Thickness of Slab & \\
\hline
\end{tabular}




\section{Building Models}

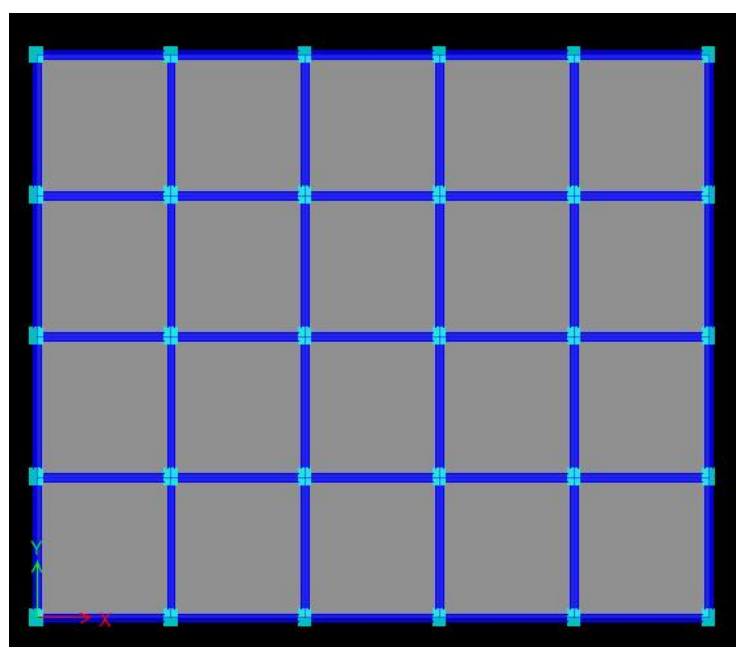

Figure 1: Regular Model

The models which are considered for the present work are developed using ETABS-2015 structural software. The models are shown in below figures

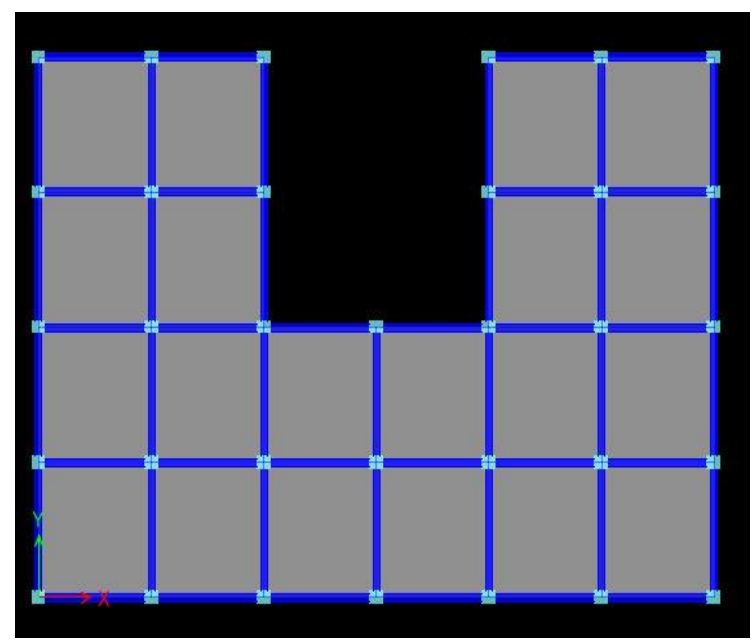

Figure 2: C-Shape Model

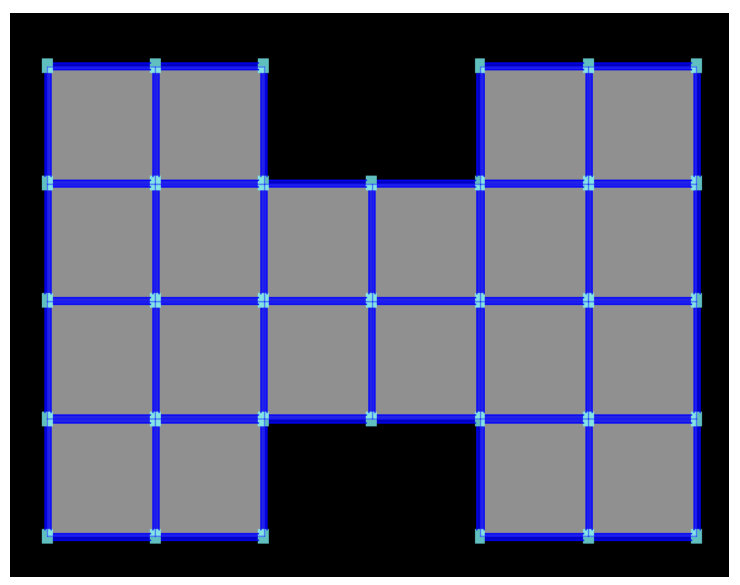

Figure 3: H-Shape Model

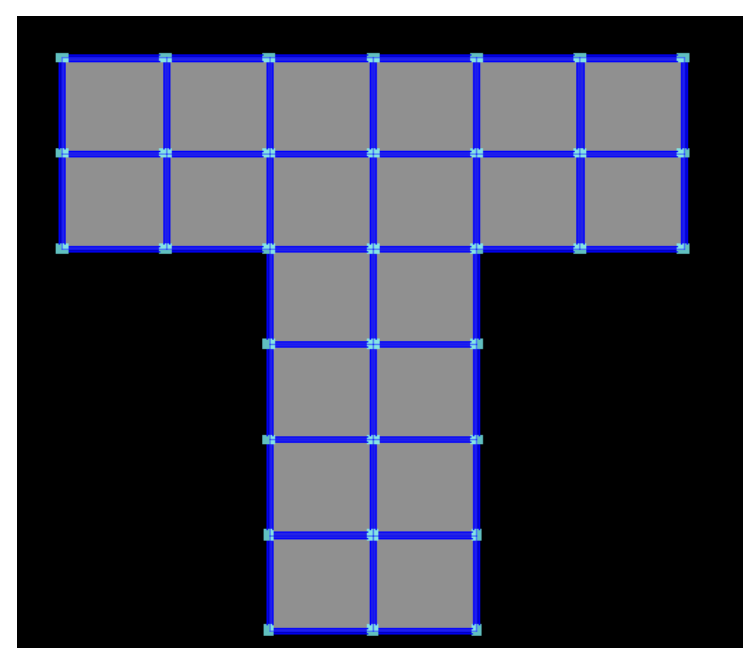

Figure 4: T-Shape Model

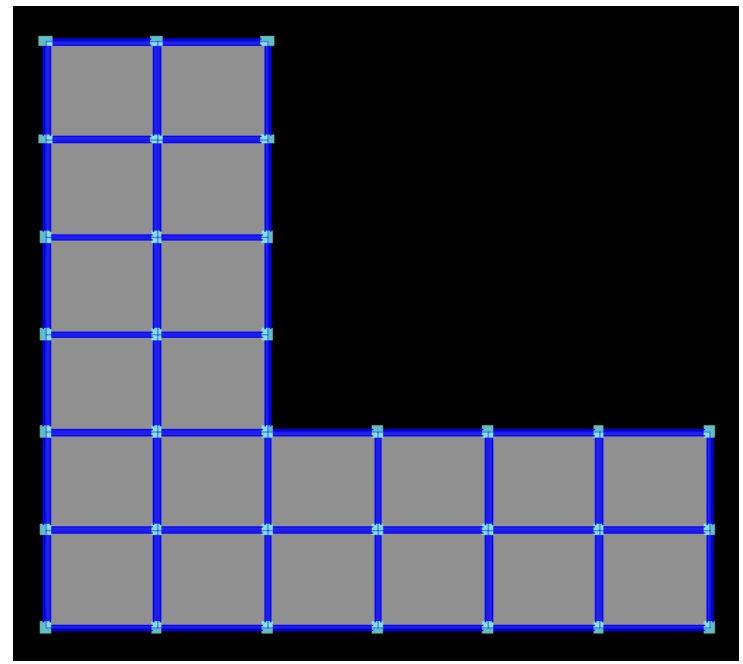

Figure 5: L-Shape Model

Live load on all the structures is taken as $3 \mathrm{kN} / \mathrm{m}^{2}$ on floor levels and roof level $1.5 \mathrm{kN} / \mathrm{m}^{2}$.Floor finish is taken as $0.5 \mathrm{kN} / \mathrm{m}^{2}$.

\section{RESULTS}

The research work is carried out to perform the seismic analysis of plan irregular buildings and to study the response of the building due to earthquake excitation. The models of plan irregular building of shape $\mathrm{C}, \mathrm{H}, \mathrm{L}$ and $\mathrm{T}$ along with regular model are developed using ETABS-2015 software. These five models are developed in different soil stratum of hard, medium and soft. Each model has a G+9 storey and located in seismic zone IV. Analysis is performed by using Response spectrum method to know the base shear of each model in different soils. The maximum displacement, storey drift, acceleration, time period and story shear are compared and discussion of the results are done in this chapter. 


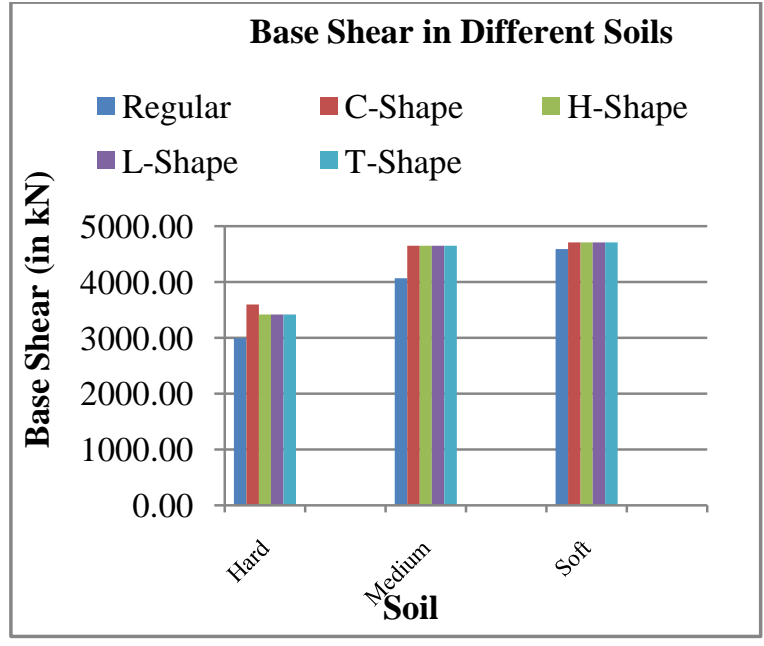

Figure 6: Base Shear in Different Soils

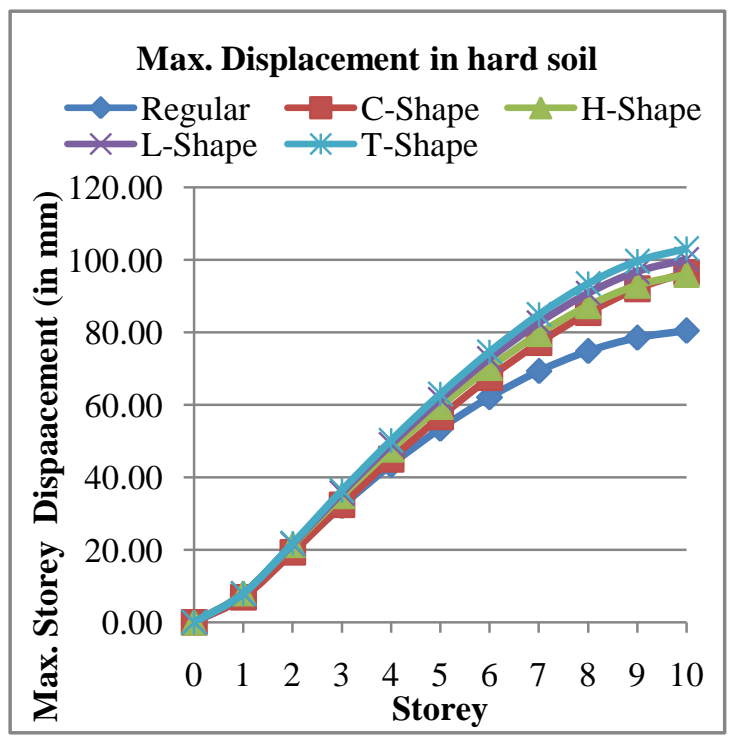

Figure 7: Displacement in Hard Soil

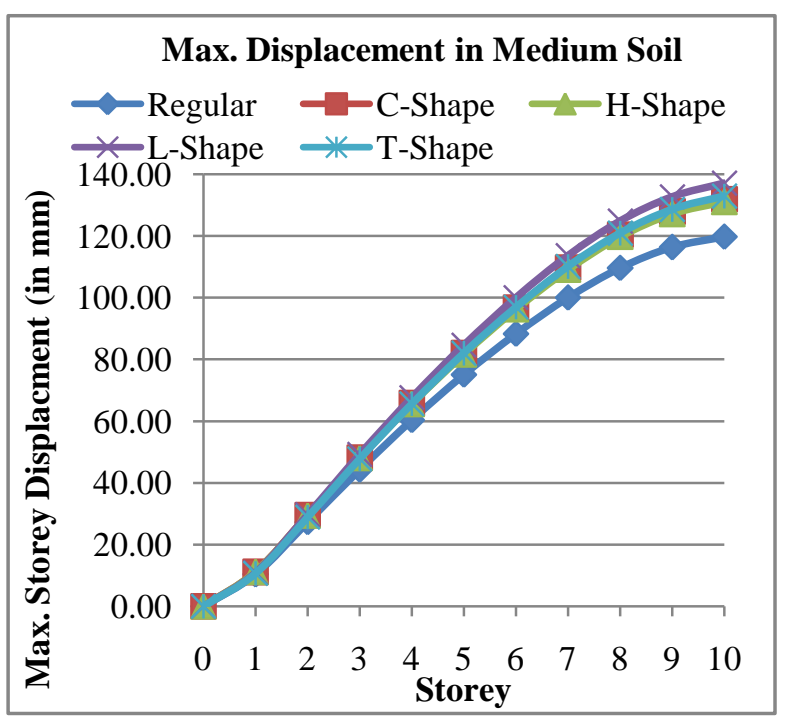

Figure 8: Storey Displacement in Medium Soil

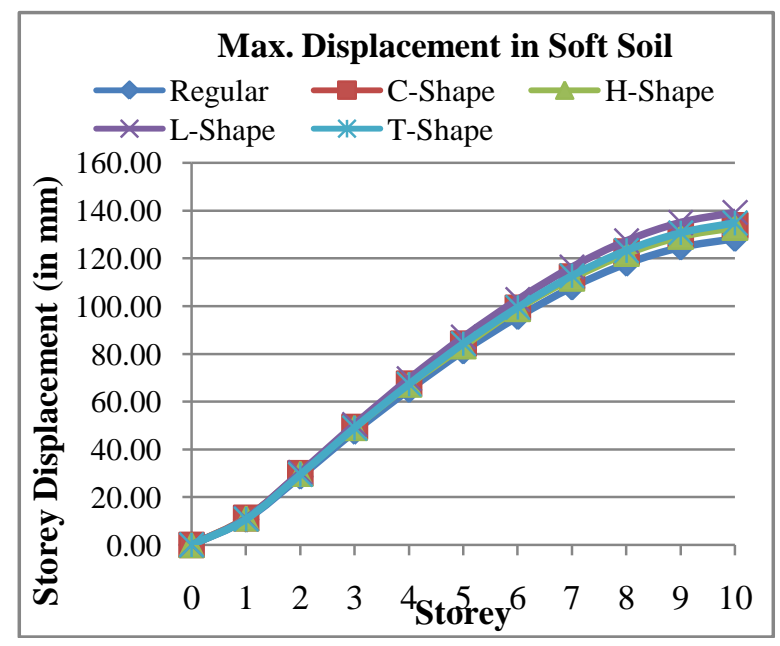

Figure 9: Storey Displacement in Soft Soil

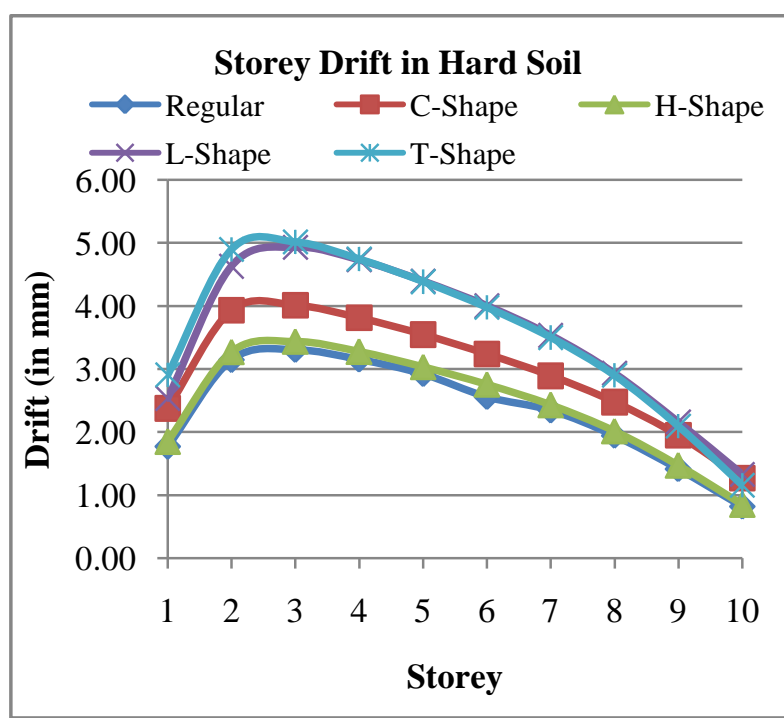

Figure 10: Storey Drift in Hard Soil

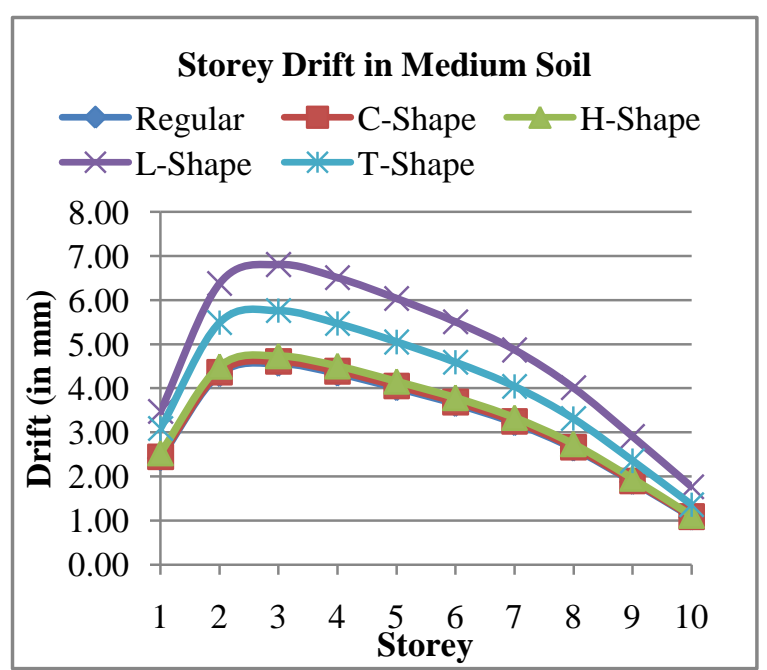

Figure 11: Storey Drift in Medium Soil 


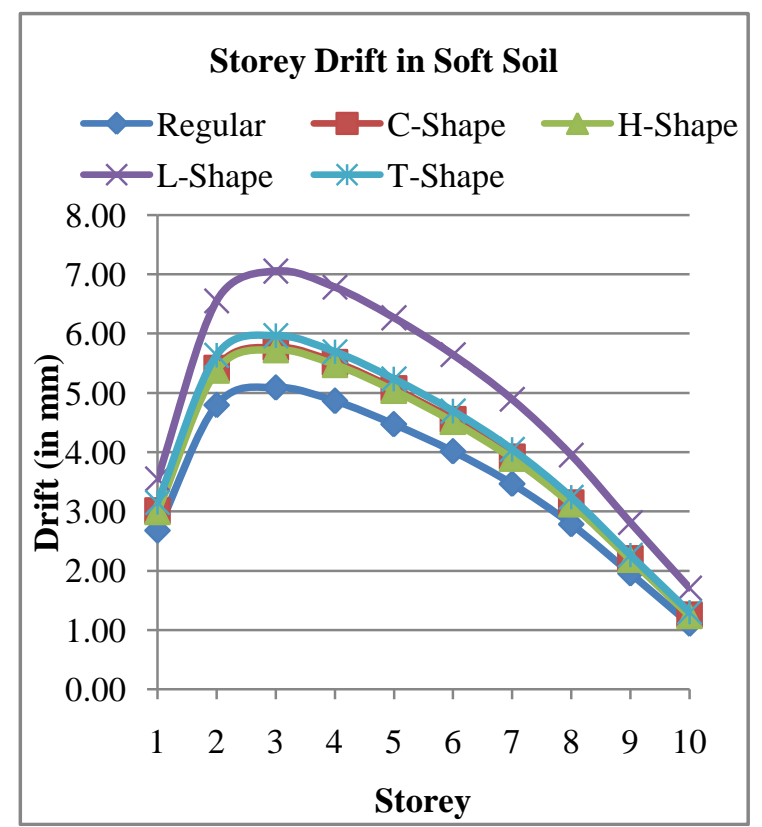

Figure 12: Storey Drift in Soft Soil

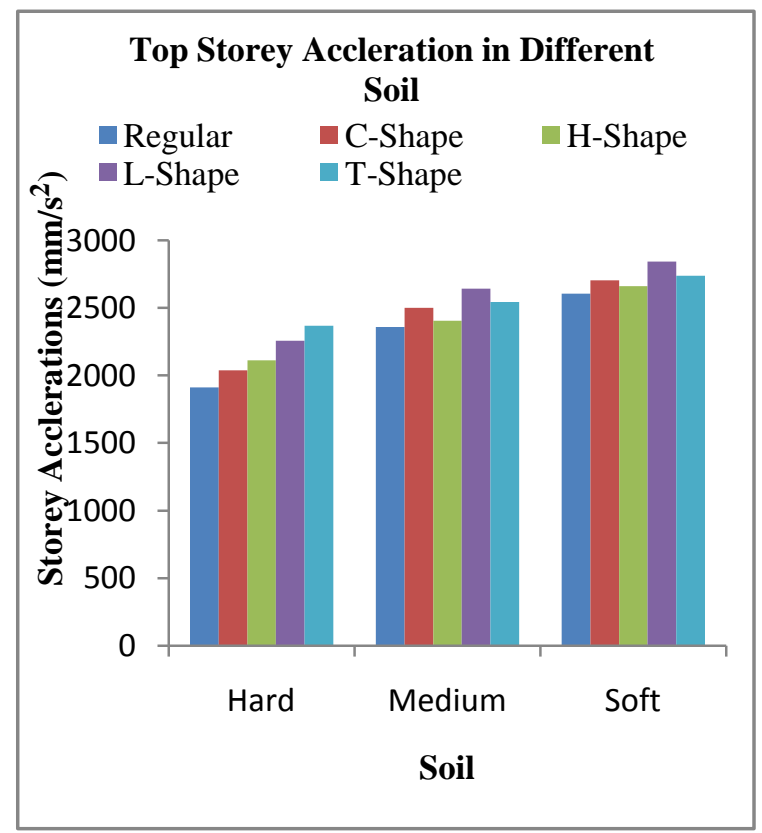

Figure 13: Top Storey Acceleration in Different Soil

Table 2: Modal Analysis Result of Regular Shape Building

\begin{tabular}{|l|l|l|l|l|l|}
\hline Modes & Time Period & \multirow{2}{*}{$\begin{array}{l}\text { Frequency } \\
\text { Cys/s }\end{array}$} & \multicolumn{3}{|l|}{ Modal Mass Participating Ratio } \\
\cline { 4 - 6 } & & X-Trans & Y-Trans & Rz-Rot \\
\hline 1 & 1.826 & 0.548 & 0.8081 & 0 & 0 \\
\hline 2 & 1.756 & 0.569 & 0 & 0.7979 & 0 \\
\hline 3 & 1.594 & 0.627 & 0 & 0 & 0.8054 \\
\hline \multicolumn{2}{|l}{ Sum of 12 Modes } & 0.9656 & 0.9617 & 0.9636 \\
\hline
\end{tabular}

Table 3: Modal Analysis Result of C-shape Building

\begin{tabular}{|l|l|l|l|l|l|}
\hline \multirow{2}{*}{ Modes } & \multirow{2}{*}{ Time Period } & Frequency & \multicolumn{4}{|l|}{ Modal Mass Participating Ratio } \\
\cline { 4 - 6 } & & Cys & X-Trans & Y-Trans & Rz-Rot \\
\hline 1 & 1.824 & 0.548 & 0.800 & 0 & 0.006 \\
\hline 2 & 1.721 & 0.581 & 0 & 0.797 & 0 \\
\hline 3 & 1.614 & 0.620 & 0.006 & 0 & 0.797 \\
\hline \multicolumn{2}{|l|}{ Sum of 12 Modes } & 0.965 & 0.962 & 0.963 \\
\hline
\end{tabular}

Table 4: Modal Analysis Result of H-Shape Building

\begin{tabular}{|l|l|l|l|l|l|}
\hline Modes & Time Period & \multirow{2}{*}{$\begin{array}{l}\text { Frequency } \\
\text { Cys/s }\end{array}$} & \multicolumn{3}{|c|}{ Modal Mass Participating Ratio } \\
\cline { 4 - 6 } & & & $X$-Trans & Y-Trans & Rz-Rot \\
\hline 1 & 1.824 & 0.548 & 0.8061 & 0 & 0 \\
\hline 2 & 1.721 & 0.581 & 0 & 0.7974 & 0 \\
\hline 3 & 1.614 & 0.62 & 0 & 0 & 0.8016 \\
\hline \multicolumn{2}{|l}{ Sum of 12 Modes } & 0.9652 & 0.9616 & 0.9627 \\
\hline
\end{tabular}

Table 5: Modal Analysis Result of L-Shape Building

\begin{tabular}{|l|l|l|l|l|l|}
\hline Modes & Time Period & \multirow{2}{*}{$\begin{array}{l}\text { Frequency } \\
\text { Cys/s }\end{array}$} & \multicolumn{3}{|c|}{ Modal Mass Participating Ratio } \\
\cline { 4 - 6 } & & X-Trans & Y-Trans & Rz-Rot \\
\hline 1 & 1.810 & 0.552 & 0.780 & 0 & 0.018 \\
\hline 2 & 1.753 & 0.570 & 0.011 & 0.688 & 0.097 \\
\hline 3 & 1.647 & 0.607 & 0.012 & 0.107 & 0.683 \\
\hline Sum of 12 Modes & & 0.964 & 0.962 & 0.962 \\
\hline
\end{tabular}

Table 6: Modal Analysis Result of T-Shape Building

\begin{tabular}{|c|c|c|c|c|c|}
\hline \multirow[t]{2}{*}{ Modes } & \multirow[t]{2}{*}{ Time Period } & \multirow{2}{*}{$\begin{array}{l}\text { Frequency } \\
\text { Cys/s }\end{array}$} & \multicolumn{3}{|c|}{$\begin{array}{l}\text { Modal Mass } \\
\text { Participating Ratio }\end{array}$} \\
\hline & & & X-Trans & Y-Trans & Rz-Rot \\
\hline 1 & 1.803 & 0.555 & 0 & 0.8041 & 0 \\
\hline 2 & 1.784 & 0.560 & 0.5374 & 0 & 0.2616 \\
\hline 3 & 1.646 & 0.608 & 0.2613 & 0 & 0.5411 \\
\hline \multicolumn{3}{|c|}{ Sum of 12 Modes } & 0.9621 & 0.9643 & 0.9636 \\
\hline
\end{tabular}

\section{CONCLUSION}

1. The base shear of models increases when soil support condition changes from hard to soft soil. Maximum base shear was found in $\mathrm{X}$ direction for all the models. The increase in regular models about $26.47 \%$ for from hard to medium, and $19.16 \%$ from medium to soft soil. The variation in others models were found nearly equal and it was $22.58 \%$ from hard to medium and nearly $1 \%$ from medium to soft soil.

2. The displacement undergone by each storey is greater in case of L-Shape model when compared to other models in soft and medium soil.

3. The ground acceleration to which the structure is subjected is higher in soft soil when compared to hard soil. The peak acceleration increases when soil stratum changes from hard soil to soft soil.

4. The storey drift experienced by the building is higher in soft soil and least in hard soil.

5. The modal time periods obtained from response spectrum analysis implicates that the regular buildings have longer time periods than re-entrant buildings.

6. As re-entrant buildings have lesser time periods, they are more susceptible to ground motions and the probability of undergoing damage due to high frequency ground motions is high.

7. With all the results from the analysis performed in this study we can conclude that regular building is more stable in all soils in seismic zone IV when compared to irregular models taken for the study. Among irregular models $\mathrm{C}$ and $\mathrm{H}$ gives better results than $\mathrm{L}$ and $\mathrm{T}$. 


\section{REFERENCES}

[1] S. Vardarajan, V.K. Sehgal and B. Saini, "Review of Different Structural Irregularities in Buildings", Journal of Structural Engineering, Vol. 39, No. 5, Pp. 393-418, 2012-2013.

[2] V.K. Sadashiva, G.A Macrae and B.L Deam, "Determination of Irregularity Limits", The 14th World Conference of Earthquake Engineering, Beijing, China, 2008.

[3] V.K Sadashiva, G.A. Macrae and B.L. Deam, "Simple Method to Evaluate Structural Irregularity Effects", Conference of New Zealand Society for Earthquake Engineering, 2010.

[4] Y. Zhou and X. Lu, "Seismic Performance Evaluation of an Irregular High Rise Building", 4th International Conference on Earthquake Engineering, Taipei, Taiwan, Pp. 99, 2006.

[5] A.U. Salunke, Dr.S.B. Kadam and Dr.S.N. Tande, "Behaviour of RC InFilled Building with Different Configuration of Plan under Seismic Force", IJIET, Vol. 5, No. 2, Pp. 78-81, 2015.

[6] Joheb Ahmed and Syed Ahamed Raza, "Seismic Vulnerability of RC Buildings by Considering Plan Irregularities Using Pushover Analysis", GJRA, Vol. 3, No. 9, Pp. 42-47, 2014.

[7] Y. Mohammed and P.M. Shimpale, "Dynamic Analysis of Reinforced Concrete Building With Plan Irregularities", IJETAE, Vol.3, No. 9, Pp. 110-116, 2013.

[8] C.M. Ravi Kumar, K.S. Babu Narayan, B.V. Sujit and D. Venkat Reddy, "Effect of Irregular Configuration on Seismic Vulnerability of RC Buildings", Architecture Research, Vol. 2, No. 3, Pp. 20-26, 2012.

[9] M.R Sultan and D.G. Peera, "Dynamic Analysis Multi Storey Building for Different Shapes", IJIRAE, Vol. 2, No. 8, Pp. 85-91, 2015.

[10] M.R.. Wakchaure, A. Shirish and R. Nikam, "Study of Plan Irregularity on High-Rise Structures", International Journal of Innovative Research and Development, Vol. 1, No. 8, Pp. 269-281, 2012.

[11] S.H. Jeong and A.S. Elnashai, "Fragility Analysis of Buildings with Plan Irregularities", In 4th International Conference on Earthquake Engineering (4ICEE), Pp. 12-13, 2006

[12] T. Madhi and V. SoltanGharaie, "Plan Irregular RC Frames: Comparison of Pushover with Non Linear Dynamic Analysis", Asian Journal of Civil Engineering (Building and Housing), Vol. 12, No. 6, 2011, Pp. 679-690.

[13] R. Komal, Bele and S.B. Borghate, "Dynamic Analysis of Building with Plan Irregularity", Journal of Civil Engineering and Environment Technology, Vol. 2, No. 11, Pp. 23-30, 2015.

[14] C. Shreyasvi and B. Shivakumarswamy, "Seismic Response of Building with Re-Entrant Corners in Different Seismic Zones”, IJRET, Vol. 4, No. 4, 2015, pp. 55-60.

[15] N.P. Modakwar, S.S. Meshram and D.W. Gawatre, "Seismic Analysis of Structures with Irregularities. IOSR Journal of Mechanical and Civil Engineering, Pp. 63-66, 2014.

[16] R.G. Herrera and C.G. Soberon, "Influence of plan irregularity of buildings," In The 14th World Conference on Earthquake Engineering, 2008.

[17] IS: 1893-2002 Indian Standard-Criteria for Earthquake Resistant Design of Structures, Part-1, General Provisions and Buildings, Bureau of Indian Standards, New Delhi, 2002.

[18] IS 456-2000: Plain and Reinforced Concrete-Code of Practice, BIS, New Delhi, India. 